\title{
Dysgonomonas gen. nov. to accommodate Dysgonomonas gadei sp. nov., an organism isolated from a human gall bladder, and Dysgonomonas capnocytophagoides (formerly CDC group DF-3)
}

\author{
Tor Hofstad, ${ }^{1}$ Ingar Olsen, ${ }^{2}$ Emenike R. Eribe, ${ }^{2}$ Enevold Falsen, ${ }^{3}$ \\ Matthew D. Collins ${ }^{4}$ and Paul A. Lawson ${ }^{4}$
}

\begin{abstract}
Author for correspondence: Paul A. Lawson. Tel: +44 118935 7224. Fax: +44 1189357222 e-mail: p.a.lawson@reading.ac.uk
\end{abstract}

\footnotetext{
1 Department of Microbiology and Immunology, University of Bergen, The Gade Institute, N-5021, Bergen, Norway

2 Department of Oral Biology, Dental Faculty, University of Oslo, $\mathrm{N}-0316$ Oslo, Norway

3 Culture Collection, Department of Clinical Bacteriology, University of Göteborg, Göteborg, S-413 46, Sweden

4 Department of Food Science and Technology, University of Reading, Whiteknights, PO Box 226, Reading RG6 6AP, UK
}

\begin{abstract}
Results of a polyphasic taxonomic study on an unknown Gram-negative, facultatively anaerobic, coccobacillus-shaped organism isolated from an infected human gall bladder are presented. Phenotypic and molecular taxonomic studies revealed the organism to be close to, but distinct from, organisms designated CDC (Centers for Disease Control and Prevention) group DF-3. The unknown bacterium was readily distinguished from reference strains of Bacteroides, Prevotella, Porphyromonas and related taxa by 165 rRNA gene sequencing, biochemical tests, analysis of cellular long-chain fatty acids and electrophoretic analysis of whole-cell proteins. Based on the results of the present study, it is proposed that the unknown bacterium be classified in a new genus, Dysgonomonas, as Dysgonomonas gadei sp. nov. (type strain CCUG $\mathbf{4 2 8 8 2}^{\mathrm{T}}=$ CIP 106420 $^{\mathrm{T}}$ ). In addition, a new species, Dysgonomonas capnocytophagoides sp. nov., is proposed to accommodate strains previously belonging to CDC group DF-3. The type species of the genus Dysgonomonas is Dysgonomonas gadei.
\end{abstract}

Keywords: taxonomy, phylogeny, Dysgonomonas, CDC group DF-3, 16S rRNA

\section{INTRODUCTION}

CDC (Centers for Disease Control and Prevention) group DF-3 (dysgonic fermenter 3) is a group of hitherto unclassified, fastidious, facultatively anaerobic, Gram-negative coccobacilli (Wallace et al., 1989). CDC group DF-3 strains grow slowly on blood agar medium, but not on MacConkey agar, ferment several carbohydrates, hydrolyse aesculin, do not reduce nitrate, and are catalase- and oxidase-negative. These organisms have a distinct cellular fatty acid profile characterized by large amounts of straightchain saturated, anteiso- and iso-methyl branched, and 3-hydroxy long-chain fatty acids (Wallace et al., 1989). Comparative 16S rRNA sequence analysis has

Abbreviation: $C D C$, Centers for Disease Control and Prevention.

The GenBank accession number for the 16S rRNA gene sequence of Dysgonomonas gadei strain CCUG $42882^{\top}$ is $\mathrm{Y} 18530$. indicated that CDC group DF-3 is phylogenetically related to, but nevertheless distinct from Bacteroides, Porphyromonas, Prevotella and related species (Paster et al., 1994; Vandamme et al., 1996). CDC DF-3 isolates are resistant to several antimicrobial agents, including penicillins, cephalosporins, aminoglycosides and ciprofloxacin. Most isolates are susceptible to clindamycin, tetracycline, chloramphenicol, imipenem and trimethoprim/sulfamethoxazole (Gill et al., 1991; Blum et al., 1992). CDC group DF-3 organisms are relatively rare isolates that have been recovered from stool samples, mainly in immunocompromised patients and patients with severe underlying diseases (Blum et al., 1992; Heiner et al., 1992), but also from clinical materials such as blood, wounds and abscesses (Aronson \& Zbick, 1988; Bangsborg et al., 1990). The pathogenic potential of the organisms remains unknown. The isolation of organisms with biochemical properties similar, but not identical, to those of CDC group DF-3 (designated CDC group DF-3-like 
organisms) has also been reported (Daneshvar et al., 1991).

In this study, the cultural and biochemical properties, cellular fatty acid composition and SDS-PAGE protein profile of an isolate, which resembles CDC group DF-3 organisms, recovered from an infected gall bladder are reported. In addition, results of 16S rRNA gene sequencing indicate that the organism represents a new species that clusters together with CDC group DF-3 organisms. It is therefore proposed that a new genus, Dysgonomonas, be created to accommodate the new organism isolated from an infected gall bladder classified as Dysgonomonas gadei sp. nov. (type strain CCUG $42882^{\mathrm{T}}=$ CIP $106420^{\mathrm{T}}$ ) and organisms previously designated CDC group DF-3 be classified as Dysgonomonas capnocytophagoides sp. nov. The type species of the genus Dysgonomonas is Dysgonomonas gadei.

\section{METHODS}

Source of the organism. Strain CCUG $42882^{\mathrm{T}}$ was originally isolated from a 68 -year-old male with known non-insulindependent diabetes mellitus and essential hypertension. The patient was admitted to hospital because of fractures of the left tibia and the left third, fourth and fifth metatarsal bones following a car accident. Treatment was conservative. Nine days later, the patient was suddenly ill with fever, chills and vascular collapse. Escherichia coli was recovered in blood cultures. Ultrasound scanning of the abdomen, performed a few days later, showed gallstones and a distended gall bladder. Aerobic and anaerobic cultivation of pus (which contained no trace of bile) aspirated from the gall bladder yielded growth of E. coli, a Klebsiella species and enterococci. In addition, a slow-growing, Gram-negative coccobacillus was recovered by anaerobic cultivation on kanamycin/ vancomycin laked blood agar. The patient was treated with cefuroxime and metronidazole for 2 weeks and recovered uneventfully.

Cultural and biochemical characterization. The unknown Gram-negative coccobacillus from the infected gall bladder was cultured aerobically at $35^{\circ} \mathrm{C}$ in a thermostat supplemented with $7.5 \% \mathrm{CO}_{2}$ on Fastidious Anaerobic Agar (FAA; Lab M) and Columbia agar base (Difco), both of which were supplemented with $5 \%$ human blood. Growth requirements for $\mathrm{X}$ and $\mathrm{V}$ factors were examined using discs impregnated with $\mathrm{X}$ factor, $\mathrm{V}$ factor or both, and nutrient agar as basal medium. Bile sensitivity was determined by the Oxgall test using Diatabs diagnostic tablets (Rosco) as described by Weinberg et al. (1983). The strain was biochemically characterized by using a combination of conventional tests and the API ID32A, API ID32E and API ZYM systems according to the manufacturer's instructions (API bioMérieux).

Susceptibility to antimicrobial agents. MICs of a range of antibacterial agents, including penicillins, cephalosporins, glycopeptide antibiotics, aminoglycosides, fluoroquinolones, macrolides, quinolones, chloramphenicol, doxycycline, metronidazole, sulphadiazine and trimethoprim/ sulphamethoxazole, were examined using the E-test (AB Biodisk). The tests were performed as recommended by the manufacturers and read after incubation aerobically for $2 \mathrm{~d}$.
MIC of metronidazole was determined after $2 \mathrm{~d}$ anaerobic incubation (Mart Anoxomat system; Mart Microbiology Automation). FAA, supplemented with 5\% human blood, was used as growth medium instead of PDM Antibiotic Sensitivity medium because of poor growth on the latter, even when supplemented with $5 \%$ horse blood.

SDS-PAGE of whole-cell proteins. To assess the overall phenotypic resemblance of the new isolate and reference species, a comparative analysis of whole-cell protein profiles by SDS-PAGE was performed. PAGE analysis of whole-cell proteins was performed as described by Pot et al. (1994) and Vandamme et al. (1998). For densitometric analysis, normalization and interpretation of protein patterns the GCW 3.0 software package (Applied Maths) was used. The similarity between all pairs of traces was expressed by the Pearson product-moment correlation coefficient, converted for convenience to a percentage similarity.

Long-chain cellular fatty acid analysis. Cells were cultured on chocolate agar using Columbia agar base and incubated for $48 \mathrm{~h}$ at $37^{\circ} \mathrm{C}$ and centrifuged. Saponification, methanolysis, extraction and identification of the fatty acid methyl esters were made using the Microbial Identification system (Microbial ID) as described previously (Moore et al., 1994; Debelian et al., 1997).

Determination of 16S rRNA gene sequences and phylogenetic analysis. Phylogenetic determination was performed by comparative 16S rRNA gene sequence analyses. A large fragment of the 16S rRNA gene (corresponding to positions 30-1521 of the E. coli $16 \mathrm{~S}$ rRNA gene) was amplified by PCR using conserved primers close to the $3^{\prime}$ and $5^{\prime}$ ends of the gene. The PCR products were directly sequenced using a $T a q$ dye-deoxy terminator cycle sequencing kit (Applied Biosystems) and an automatic DNA sequencer (model 373A; Applied Biosystems). The closest known relatives of the new isolate were determined by performing a database search using the program FASTA of the Genetics Computer Group package (Pearson \& Lipman, 1985). These sequences and those of other known related strains were retrieved from the EMBL or Ribosomal Database Project databases and aligned with the newly determined sequences using the program PILEUP (Devereux et al., 1984). The resulting multiple sequence alignment was corrected manually and approximately 100 bases at the $5^{\prime}$ end of the rRNA were omitted from further analyses because of alignment ambiguities. Pairwise evolutionary distances were then computed from a continuous stretch of 1320 bases using the correction of Jukes \& Cantor (1969). A phylogenetic tree was constructed according to the neighbour-joining method with the program NEIGHBOR (Felsenstein, 1989). The stability of the groupings was estimated by bootstrap analysis (500 replications) using the programs SEQBOOT, DNADIST, NEIGHBOR and CONSENSE (Felsenstein, 1989).

\section{RESULTS}

\section{Cultural and biochemical properties}

The isolate originating from the infected gall bladder consisted of non-motile, Gram-negative coccobacilli that grew relatively slowly on blood agar. The organism grew with or without the addition of $7.5 \%$ $\mathrm{CO}_{2}$, in addition to growing anaerobically. After $48 \mathrm{~h}$ incubation aerobically at $35^{\circ} \mathrm{C}$ in a $\mathrm{CO}_{2}$-enriched atmosphere $(7.5 \%)$, the colonies were $1-2 \mathrm{~mm}$ in 

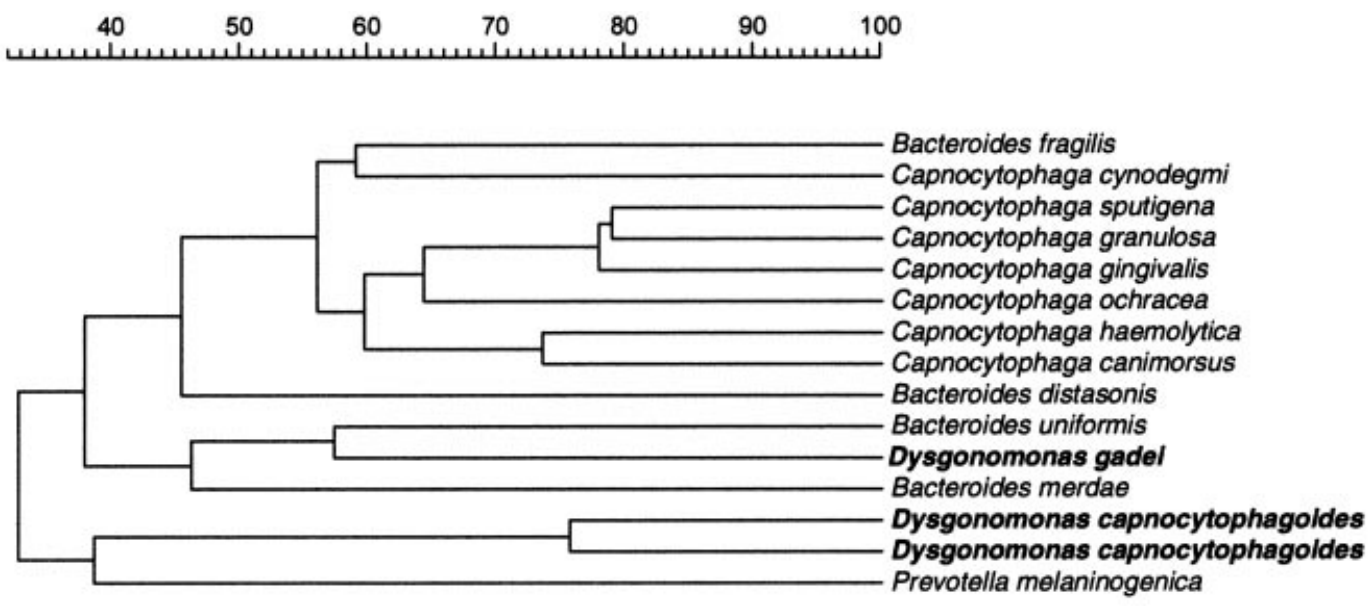

Fig. 1. Similarity dendrogram based on whole-cell protein patterns of Dysgonomonas gen. nov., sp. nov. and related species. Levels of correlation are expressed as percentages of similarity for convenience.

diameter, non-adherent, entire, grey-white, smooth and non-haemolytic, and had a slightly aromatic odour. Following incubation for a few more days, the colonies were somewhat coalesced, butyrous and $\alpha$ haemolytic. Growth was obtained at $25^{\circ} \mathrm{C}$, but not at $43^{\circ} \mathrm{C}$. Growth was not observed on MacConkey agar. The coccobacillus grew on nutrient agar around $X$ and $\mathrm{XV}$ discs, suggesting a growth factor dependency for haem. The organism grew under microaerophilic and strictly anaerobic conditions. It was catalase-positive and oxidase-negative, it failed to reduce nitrate, and it did not produce hydrogen sulphide or acetoin, but did produce indole. Aesculin was hydrolysed, but gelatin and urea were not. Growth and precipitation were observed around the Oxgall tablets demonstrating that the organism was resistant to ox bile. Glucose was fermented with production of acid but no gas. Acid was produced from L-arabinose, cellobiose, fructose, lactose, D-mannose, raffinose, L-rhamnose, D-ribose (weak reaction), salicin, starch, sucrose and trehalose. Adonitol, dulcitol, erythritol, glycogen, inositol, D-mannitol and D-sorbitol were not acidified. Positive reactions were obtained for $N$-acetyl- $\beta$-glucosaminidase, acid phosphatase, alanine arylamidase, alkaline phosphatase, $\alpha$-arabinosidase, ester lipase C8 (weak reaction), $\alpha$-galactosidase, $\beta$-galactosidase, $\alpha$ glucosidase, $\beta$-glucosidase, $\beta$-glucuronidase, glutamyl glutamic acid arylamidase, $\alpha$-mannosidase (weak reaction), $\alpha$-fucosidase, chymotrypsin, alanine arylamidase, leucyl glycine arylamidase, phosphoamidase and trypsin. Arginine dihydrolase, arginine arylamidase, cystine arylamidase, esterase C-4, $\beta$ galactosidase 6-phosphate, glutamic acid decarboxylase, glycine arylamidase, histidine arylamidase, lipase $\mathrm{C} 14$, leucine arylamidase, phenylalanine arylamidase, proline arylamidase, pyroglutamic acid arylamidase, serine arylamidase, tyrosine arylamidase, urease and valine arylamidase were not detected. Results for the production of $\beta$-glucuronidase differed between the different API systems employed. Using the API ID32A and rapid ID32E systems, $\beta$-glucuronidase was detected, but with the API ZYM kit this enzyme was not produced. The API rapid ID32A profile for the unknown bacterium was 4577640222 when compared to 4736440202 obtained for DF-3 strains CCUG $17996^{\mathrm{T}}$ and CCUG 42515.

\section{SDS-PAGE of whole-cell proteins}

A numerical analysis of the whole-cell protein patterns of the unknown bacterium and two CDC group DF-3 strains (CCUG 17996, CCUG 42515) together with reference strains of Bacteroides, Capnocytophaga and Prevotella is shown in Fig. 1. The unknown gall bladder isolate was shown to be separate from the two DF-3 strains and all reference strains used. The nearest correlation was with Bacteroides uniformis at a level of approximately $58 \%$. In addition, the two CDC DF-3 strains clustered together with a correlation level of about $75 \%$.

\section{Susceptibility to antimicrobial agents}

The unknown clinical isolate was sensitive to metronidazole (MIC 1.5 $\mathrm{g} \mathrm{ml}^{-1}$ ), clindamycin (MIC $0.25 \mu \mathrm{g} \mathrm{ml}^{-1}$ ), doxycycline (MIC $0.19 \mu \mathrm{g} \mathrm{ml}^{-1}$ ), imipenem (MIC $0.5 \mu \mathrm{g} \mathrm{ml}^{-1}$ ), meropenem (MIC $0.064 \mu \mathrm{g} \mathrm{ml}^{-1}$ ) and trimethoprim/sulphamethoxazole (MIC $0.125 \mu \mathrm{g} \mathrm{ml}^{-1}$ ). The organism was resistant to cefoxitin (MIC $24 \mu \mathrm{g} \mathrm{ml}^{-1}$ ) and the other cephalosporins tested [cefotaxime, cefpirome, ceftazidime, ceftriaxone, cefuroxime and cephalothin (MIC $\left.\left.256 \mu \mathrm{g} \mathrm{ml}^{-1}\right)\right]$. In addition, the isolate was resistant to the aminoglycosides [gentamicin (MIC $256 \mu \mathrm{g} \mathrm{ml}^{-1}$ ), netilmicin (MIC $256 \mu \mathrm{g} \mathrm{ml}^{-1}$ ) and sulphadiazine (MIC $256 \mu \mathrm{g} \mathrm{ml}^{-1}$ )], fluoroquinolones [ciprofloxacin (MIC $32 \mu \mathrm{g} \mathrm{ml}^{-1}$ ) and oxafloxacin (MIC $8 \mu \mathrm{g} \mathrm{ml}^{-1}$ )] and the 
Table 1. Composition (\%) of cellular fatty acids in strain CCUG $42882^{\top}$ and CDC group DF-3 strains CCUG $17996^{\top}$ and 42515

ND, Not detected.

\begin{tabular}{|c|c|c|c|}
\hline \multirow[t]{2}{*}{ Fatty acid } & \multicolumn{3}{|c|}{ Strain } \\
\hline & DF-3 CCUG 17996 & DF-3 CCUG 42515 & CCUG $42882^{\mathrm{T}}$ \\
\hline iso- $\mathrm{C}_{12: 0}$ & $\mathrm{ND}$ & $0 \cdot 3$ & 1.9 \\
\hline $\mathrm{C}_{13: 0}$ & $\mathrm{ND}$ & $0 \cdot 9$ & ND \\
\hline iso- $\mathrm{C}_{13: 0}$ & $9 \cdot 5$ & 0.5 & $0 \cdot 9$ \\
\hline anteiso- $\mathrm{C}_{13: 0}$ & $\mathrm{ND}$ & $0 \cdot 7$ & $3 \cdot 5$ \\
\hline $\mathrm{C}_{14: 0}$ & $2 \cdot 4$ & 1.9 & 1.6 \\
\hline iso- $\mathrm{C}_{14: 0}$ & $19 \cdot 8$ & $12 \cdot 3$ & $12 \cdot 9$ \\
\hline$C_{15: 0}$ & $11 \cdot 3$ & $14 \cdot 2$ & $2 \cdot 9$ \\
\hline$C_{15: 1}$ & $3 \cdot 4$ & $2 \cdot 7$ & $\mathrm{ND}$ \\
\hline anteiso- $\mathrm{C}_{15: 0}$ & $19 \cdot 6$ & $19 \cdot 4$ & $23 \cdot 9$ \\
\hline iso- $\mathrm{C}_{15: 0}$ & $2 \cdot 7$ & $2 \cdot 2$ & $4 \cdot 0$ \\
\hline iso- $3 \mathrm{OH} \mathrm{C} \mathrm{C}_{15: 0}$ & ND & $0 \cdot 8$ & ND \\
\hline $3 \mathrm{OH} \mathrm{C} \mathrm{C}_{15: 0}$ & ND & $3 \cdot 8$ & ND \\
\hline $3 \mathrm{OH} \mathrm{C} \mathrm{C}_{16: 0}$ & $4 \cdot 6$ & $5 \cdot 3$ & $7 \cdot 9$ \\
\hline iso- $3 \mathrm{OH} \mathrm{C} \mathrm{C}_{17: 0}$ & $3 \cdot 3$ & $3 \cdot 5$ & ND \\
\hline $\mathrm{C}_{16: 0}$ & $3 \cdot 4$ & $3 \cdot 6$ & $15 \cdot 2$ \\
\hline iso- $\mathrm{C}_{16: 0}$ & ND & ND & $1 \cdot 3$ \\
\hline iso- $3 \mathrm{OH} \mathrm{C} \mathrm{C}_{16: 0}$ & $12 \cdot 3$ & $9 \cdot 3$ & $10 \cdot 5$ \\
\hline $3 \mathrm{OH} \mathrm{C} \mathrm{C}_{16: 0}$ & $4 \cdot 6$ & $5 \cdot 3$ & $7 \cdot 9$ \\
\hline $\mathrm{C}_{16: 0 \text { cis } 9}$ & $4 \cdot 7$ & $3 \cdot 9$ & $1 \cdot 2$ \\
\hline iso- $3 \mathrm{OH} \mathrm{C} \mathrm{C}_{17: 0}$ & $3 \cdot 3$ & $3 \cdot 5$ & $\mathrm{ND}$ \\
\hline $3 \mathrm{OH} \mathrm{C} \mathrm{C}_{17: 0}$ & ND & 1.6 & $0 \cdot 5$ \\
\hline anteiso- $\mathrm{C}_{17: 1}$ & $3 \cdot 2$ & ND & ND \\
\hline $2 \mathrm{OH} \mathrm{C} \mathrm{C}_{17: 0}$ & $\mathrm{ND}$ & $\mathrm{ND}$ & $1 \cdot 8$ \\
\hline $\mathrm{C}_{18: 0 i s s 9}$ & $\mathrm{ND}$ & $1 \cdot 4$ & $1 \cdot 1$ \\
\hline
\end{tabular}

glycopeptide antibiotics [vancomycin (MIC $48 \mu \mathrm{g} \mathrm{ml}^{-1}$ ) and teicoplanin (MIC $256 \mu \mathrm{g} \mathrm{ml}^{-1}$ )]. The MICs of other antibiotics tested were: ampicillin, $6 \mu \mathrm{g} \mathrm{ml}^{-1}$; amoxicillin, $6 \mu \mathrm{g} \mathrm{ml}^{-1}$; amoxicillin/ clavulanic acid, $\quad 1 \mu \mathrm{g} \mathrm{ml}^{-1}$; benzylpenicillin, $>32 \mu \mathrm{g} \mathrm{ml}^{-1}$; erythromycin, $16 \mu \mathrm{g} \mathrm{ml}^{-1}$; azithromycin, $16 \mu \mathrm{g} \mathrm{ml}^{-1}$; clarithromycin, $16 \mu \mathrm{g} \mathrm{ml}^{-1}$; and chloramphenicol, $4 \mu \mathrm{g} \mathrm{ml}^{-1}$.

\section{Cellular fatty acid composition}

The percentage fatty acid compositions of strain CCUG $42882^{\mathrm{T}}$ and CDC group DF-3 strains (CCUG 17996 and CCUG 42515) are given in Table 1 . The fatty acids of the unknown isolate CCUG $42882^{\mathrm{T}}$ were found to be iso- $\mathrm{C}_{14: 0}$, anteiso- $\mathrm{C}_{15: 0}, \mathrm{C}_{16: 0}$ and iso- $3 \mathrm{OH}$ $\mathrm{C}_{16: 0}$. This fatty acid pattern was similar to those of the two reference CDC group DF-3 strains examined.

\section{Phylogenetic analysis}

To investigate the genealogical affinity between the unknown bacterium and its relationship with other Gram-negative taxa, comparative 16S rRNA gene sequence analysis was performed. The almost complete gene sequence $(>1400 \mathrm{nt})$ of the unknown isolate was determined. Sequence searches of GenBank and RDP databases revealed that the unknown isolate was phylogenetically most closely associated with members of the genera Bacteroides, Prevotella and Porphyromonas, which belong to the Bacteroides subgroup of the flavobacterium-bacteroides subphylum. A tree constructed by the neighbour-joining method depicting the phylogenetic affinity of the unknown coccobacillus is shown in Fig. 2. The unknown bacterium was phylogenetically placed on the periphery of members of the genus Porphyromonas clustering with CDC group DF-3 strain CCUG 17996. 


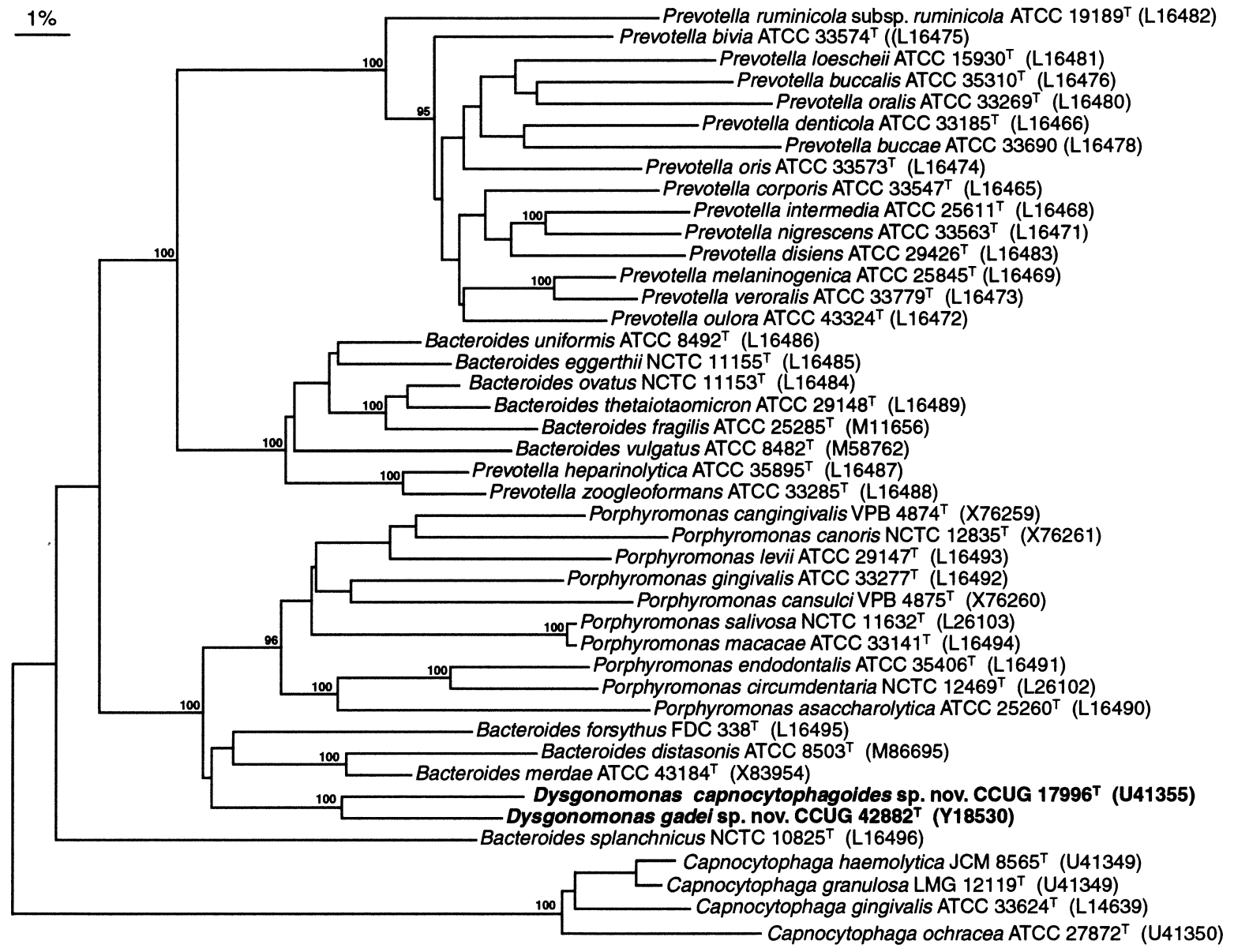

Fig. 2. Unrooted tree showing the phylogenetic relationships of Dysgonomonas species and some related Gram-negative bacteria. The tree constructed using the neighbour-joining method was based on a comparison of approx. $1327 \mathrm{nt}$. Bootstrap values, expressed as a percentage of 500 replications, are given at branching points. Scale bar, $1 \%$ sequence divergence.

A second strain belonging to $\mathrm{CDC}$ group $\mathrm{DF}-3$ (CCUG 42515) was found to be identical to CCUG $17996(100 \%$ sequence similarity in 1420 bases compared). The sequence divergence between strain CCUG $42882^{\mathrm{T}}$ and CDC group DF-3 strains was $7 \%$.

\section{DISCUSSION}

It is evident from the findings of this investigation that the bacterium originating from a human gall bladder infection represents a hitherto unrecognized species within the Bacteroides subgroup of the flavobacterium-bacteroides subphylum. Phylogenetically, the coccobacillus-shaped bacterium clustered together with strain CDC group DF-3 (93\% sequence similarity) and bootstrap resampling showed this relationship to be statistically significant $(100 \%$ recovery in 500 resamplings). Other taxa displayed significantly lower levels of sequence similarity including Bacteroides (85-87\%), Porphyromonas (84$88 \%$ ) and Prevotella (79-85\%) and the misclassified strict anaerobes Bacteroides distasonis (86\% sequence similarity), Bacteroides forsythus (89\% sequence similarity), Bacteroides merdae (89\% sequence similarity) and Bacteroides splanchnicus (83\% sequence similarity) (Fig. 2). Based on tree topology considerations and sequence divergence values, it is clear that the unknown bacterium cannot be assigned to any of the currently described genera. The association between the unknown bacterium and the CDC group DF-3 strains is, however, very significant and the depth of the cluster formed by the two taxa is indicative of a single genus. Chemotaxonomic findings (analysis of whole-cell proteins and long-chain fatty acids) and its facultative nature also demonstrate the separateness of the unknown clinical isolate from currently named members of the Bacteroides subgroup and strongly support its affinity with the CDC group DF-3 strains, which also exhibit a facultative mode of respiration. Until a more complete inventory of the organisms present within this supercluster of bacteria is established, it is not possible to draw conclusions on the significance of the association of facultative organisms with strict anaerobes. The recovery of the newly 
described organism from the diseased gall bladder may be indicative that it was present as an opportunistic pathogen. Moore et al. (1994) found that anteiso$\mathrm{C}_{15: 0}$, iso- $\mathrm{C}_{15: 0}$, iso- $3 \mathrm{OH} \mathrm{C} \mathrm{C}_{17: 0}$ and $\mathrm{C}_{16: 0}$ are the major cellular fatty acids in Bacteroides and Prevotella. These findings were consistent with earlier studies (Miyagawa et al., 1979; Shah \& Collins 1980; Mayberry et al., 1982). There is a general consensus that iso- $\mathrm{C}_{15: 0}$ is the major fatty acid in Porphyromonas strains, accounting for $33-58 \%$ of the fatty acids present (Moore et al., 1994). Therefore, the fatty acid profile of strain CCUG $42882^{\mathrm{T}}$ is incompatible with the genus Porphyromonas. The fatty acids of the aforementioned strain, however, closely resemble those reported for CDC group DF-3 strains (Daneshvar et al., 1991; Wallace et al., 1989; Table 1). Therefore, based on both phenotypic and phylogenetic findings of this and previous studies, it is proposed that the unknown Gram-negative coccobacillus and organisms previously designated CDC group DF-3 merit classification in a new genus, Dysgonomonas gen. nov., as Dysgonomonas gadei sp. nov. and Dysgonomonas capnocytophagoides sp. nov., respectively.

\section{Description of Dysgonomonas gen. nov.}

Dysgonomonas (Dys.go.no.mo'nas. N.L. n. Dysgonic a type of fermenter; Gr. fem. n. monas a monad, unit; N.L. fem. n. Dysgonomonas a monad from a Dysgonic fermenter).

Cells consist of non-motile, Gram-negative coccobacilli to short rods. Growth is not observed on MacConkey agar. Requires $\mathrm{X}$ growth factor. Facultatively anaerobic. May be catalase-positive or -negative. Oxidase-negative. Glucose is fermented producing acid but no gas. Alkaline phosphatase is produced but not arginine dihydrolase. Does not reduce nitrate. Hydrogen sulphide and acetoin are not produced. Aesculin may or may not be hydrolysed but gelatin and urea are not. Indole may or may not be produced. The long-chain cellular fatty acids are of the straight-chain saturated, anteiso- and iso-methyl branched and 3-hydroxy types. The $\mathrm{G}+\mathrm{C}$ content of DNA is $38 \mathrm{~mol} \%$ (Vandamme et al., 1996). Isolated from human clinical specimens and stool samples. Habitat is not known. The type species is Dysgonomonas gadei.

\section{Description of Dysgonomonas gadei sp. nov.}

Dysgonomonas gadei (ga'de.i. N.L. gen. masc. n. gadei of Gade Institute, Bergen, Norway where the organism was first isolated).

Cells consist of non-motile, Gram-negative coccobacilli that grow relatively slowly on blood agar. After $48 \mathrm{~h}$ incubation aerobically at $35^{\circ} \mathrm{C}$ in a $\mathrm{CO}_{2}$-enriched atmosphere, the colonies are 1-2 $\mathrm{mm}$ in diameter, nonadherent, entire, grey-white, smooth and non-haemolytic, and have a slightly aromatic odour. Following incubation for a few more days, the colonies become somewhat coalesced, butyrous and $\alpha$-haemolytic. Growth is obtained at $25{ }^{\circ} \mathrm{C}$ but not at $43{ }^{\circ} \mathrm{C}$. Grows under microaerophilic and strictly anaerobic conditions. The organism does not grow on MacConkey agar but grows on nutrient agar around $\mathrm{X}$ and $\mathrm{XV}$ discs, suggesting a growth factor dependency for haem. The organism is catalase-positive and oxidase-negative. It does not reduce nitrate or produce hydrogen sulphide or acetoin. Aesculin is hydrolysed but gelatin and urea are not. Indole is produced. Resistant to ox bile. Glucose is fermented with production of acid but no gas. Acid is produced from L-arabinose, cellobiose, fructose, lactose, D-mannose, melezitose, melibiose, raffinose, L-rhamnose, D-ribose (weak reaction), salicin, starch, sucrose, trehalose and xylose. Adonitol, dulcitol, erythritol, glycogen, inositol, D-mannitol and D-sorbitol are not acidified. Positive reactions for $N$-acetyl- $\beta$-glucosaminidase, acid phosphatase, alanine arylamidase, alkaline phosphatase, $\alpha$-arabinosidase, ester lipase C8 (weak reaction), $\alpha$-galactosidase, $\beta$-galactosidase (weak reaction), $\alpha$-glucosidase, $\beta$-glucosidase, glutamyl glutamic acid arylamidase, $\alpha$-mannosidase (weak reaction), $\alpha$ fucosidase, chymotrypsin, alanine arylamidase, leucyl glycine arylamidase, phosphoamidase and trypsin. Arginine dihydrolase, arginine arylamidase, cystine arylamidase, esterase $\mathrm{C}$-4, $\beta$-galactosidase 6phosphate, glutamic acid decarboxylase, glycine arylamidase, histidine arylamidase, lipase C14, leucine arylamidase, phenylalanine arylamidase, proline arylamidase, pyroglutamic acid arylamidase, serine arylamidase, tyrosine arylamidase, urease and valine arylamidase are not detected. The type strain of Dysgonomonas gadei is CCUG $42882^{\mathrm{T}} \quad(=\mathrm{CIP}$ $106420^{\mathrm{T}}$ ). The type strain was recovered from a human infected gall bladder. Habitat is not known.

\section{Description of Dysgonomonas capnocytophagoides sp. nov.}

Dysgonomonas capnocytophagoides (cap.no.cy.to.pha. goi'des. Gr. n. kapnos smoke; Gr. n. kytos hollow vessel; Gr. v. phagein to eat; Gr. adj. suffix -oides alike; N.L. adj. capnocytophagoides capnocytophagalike, referring to some properties shared between these organisms).

The description is based on results obtained in this study and those obtained by Wallace et al. (1989). Cells consist of non-motile, Gram-negative coccobacilli to short rods. After $48 \mathrm{~h}$ incubation aerobically at $35^{\circ} \mathrm{C}$ in a $\mathrm{CO}_{2}$-enriched atmosphere $(7.5 \%)$, the colonies are 1-2 $\mathrm{mm}$ in diameter, non-adherent, entire, grey-white, smooth and non-haemolytic and have a slight aromatic odour. The organism does not grow on MacConkey agar. Facultatively anaerobic. The organism is catalase- and oxidase-negative. It does not produce hydrogen sulphide or acetoin. Aesculin may or may not be hydrolysed but gelatin and urea are not. Indole may or may not be produced. Resistant to ox bile. Nitrate is not reduced. Major products of glucose 
fermentation are propionic, lactic and succinic acids. Glucose is fermented with production of acid but no gas. Acid is produced from L-arabinose, lactose, maltose, D-mannose, melibiose, raffinose, sucrose and D-xylose. Adonitol, D-arabitol, L-arabitol, dulcitol, inositol, D-mannitol, D-sorbitol and trehalose are not acidified. Positive reactions are obtained for acid phosphatase, alanine arylamidase, alkaline phosphatase, $\alpha$-arabinosidase, $\alpha$-galactosidase, $\beta$ galactosidase, $\beta$-galactosidase 6 -phosphate, $\alpha$-glucosidase, $\beta$-glucosidase, glutamyl glutamic acid arylamidase, leucyl glycine arylamidase and phosphoamidase. Arginine arylamidase, arginine dihydrolase, $\quad N$-acetyl- $\beta$-glucosaminidase, $\quad \alpha$-fucosidase, $\beta$-glucuronidase, glutamic acid decarboxylase, glycine arylamidase, histidine arylamidase, lysine decarboxylase, leucine arylamidase, $\alpha$-mannosidase, ornithine decarboxylase, chymotrypsin, cystine arylamidase, ester lipase $\mathrm{C} 8$, lipase $\mathrm{C} 14$, phenylalanine arylamidase, proline arylamidase, pyroglutamic acid arylamidase, serine arylamidase, tyrosine arylamidase, trypsin and valine arylamidase are not detected. Esterase C-4 production is variable. Isolated from human clinical specimens. Habitat is not known. The type strain is CCUG $17996^{\mathrm{T}}$ ( = LMG $\left.11519^{\mathrm{T}}\right)$. The $\mathrm{G}+\mathrm{C}$ content of DNA of the type strain is $38 \mathrm{~mol} \%$.

\section{ACKNOWLEDGEMENTS}

We are grateful to Hans Trüper for help in the derivation of the genus name and species epithets.

\section{REFERENCES}

Aronson, N. E. \& Zbick, C. J. (1988). Dysgonic fermenter-3 bacteremia in a neutropenic patient with acute lymphocyticleukemia. J Clin Microbiol 26, 2213-2215.

Bangsborg, J. M., Frederiksen, W. \& Bruun, B. (1990). Dysgonic fermenter 3-associated abscess in a diabetic patient. J Infect $\mathbf{2 0}$, $237-240$.

Blum, R. N., Berry, C. D., Phillips, M. G., Hamlos, D. L. \& Koneman, E. W. (1992). Clinical illness associated with isolation of dysgonic fermenter 3 from stool samples. J Clin Microbiol 30, 396-400.

Daneshvar, M. I., Hollis, D. G. \& Moss, C. W. (1991). Chemical characterization of clinical isolates which are similar to CDC group DF-3 bacteria. J Clin Microbiol 29, 2351-2353.

Debelian, G. J., Olsen, I. \& Tronstad, L. (1997). Distinction of Prevotella intermedia and Prevotella nigrescens from endodontic bacteremia through their fatty acid contents. Anaerobe 3, 61-68.

Devereux, J., Haerberli, P. \& Smithies, O. (1984). A comprehensive set of sequence analysis programs for the VAX. Nucleic Acids Res 12, 387-395.
Felsenstein, J. (1989). PHYLIP - phylogeny inference package (version 3.2). Cladistics 5, 164-166.

Gill, V. E., Travis, B. \& Williams, D. Y. (1991). Clinical and microbiological observations on CDC group DF-3, a Gram negative coccobacillus. J Clin Microbiol 29, 1589-1592.

Heiner, A. M., Disario, J. A., Carroll, K., Cohen, S., Evans, T. G. \& Shigeoka, A. O. (1992). Dysgonic fermenter-3 - a bacterium associated with diarrhoea in immunocompromised hosts. Am J Gastroenterol 87, 1629-1630.

Jukes, T. H. \& Cantor, C. R. (1969). Evolution of protein molecules. In Mammalian Protein Metabolism, pp. 21-132. Edited by N. H. Munro. New York: Academic Press.

Mayberry, W. R., Lambe, D. W., Jr \& Ferguson, K. P. (1982). Identification of Bacteroides species by fatty acid profiles. Int $J$ Syst Bacteriol 32, 21-27.

Miyagawa, E., Azuma, R. \& Suto, T. (1979). Distribution of sphingolipids in Bacteroides species. J Gen Appl Microbiol 25, 41-52.

Moore, L. V. H., Bourne, D. M. \& Moore, W. E. C. (1994). Comparative distribution and taxonomic value of cellular fatty acids in thirty-three genera of anaerobic Gram-negative bacilli. Int $J$ Syst Bacteriol 44, 338-347.

Paster, B. J., Dewhirst, F. E., Olsen, I. \& Fraser, G. J. (1994). Phylogeny of Bacteroides, Prevotella, and Porphyromonas spp. and related bacteria. J Bacteriol 176, 725-732.

Pearson, W. R. \& Lipman, D. J. (1985). Rapid and sensitive protein similarity searches. Science 227, 1435-1441.

Pot, B., Vandamme, P. \& Kersters, K. (1994). Analysis of electrophoretic whole-organism protein fingeprints. In Modern Microbial Methods. Chemical Methods in Prokaryotic Systematics, pp. 493-521. Edited by M. Goodfellow \& A. G. O'Donnell. Chichester: Wiley.

Shah, H. N. \& Collins, M. D. (1980). Fatty acid and isoprenoid quinone composition in the classification of Bacteroides melaninogenicus and related taxa. J Appl Bacteriol 48, 75-87.

Vandamme, P., Vancanneyt, M., Van Belkum, A., Segers, P., Quint, W. G. V., Kersters, K., Paster, B. J. \& Dewhirst, F. E. (1996). Polyphasic analysis of strains of the genus Capnocytophaga and Centers for Disease Control group DF-3. Int J Syst Bacteriol 46, 782-791.

Vandamme, P., Torck, U., Falsen, E., Pot, B., Goossens, H. \& Kersters, K. (1998). Whole-cell protein electrophoretic analysis of viridans Streptococcus mitis biovars. Int J Syst Bacteriol 48, $117-125$.

Wallace, P. L., Hollis, D. G., Weaver, R. E. \& Moss, C. W. (1989). Characterisation of CDC group DF-3 by cellular fatty acid analysis. J Clin Microbiol 27, 735-737.

Weinberg, L. G., Smith, L. L. \& McTighe, A. H. (1983). Rapid identification of the Bacteroides fragilis group by disk and catalase tests. Lab Med 14, 785-788. 